\title{
Introduction
}

Which factors during the first decade of the twenty-first century will be the ones to drive economic growth? Has the success of ICT (Information and Communications Technology) already given us a glimpse of the shape that will be assumed by the productive paradigm at the heart of emerging regimes? If so, how should the respective national positions of different countries be redefined? Should we expect fewer, or greater, inequalities between and within countries in terms of those that master the new technologies and those that have no access to them? Have these transformations already created an economic dynamic that is powerful and steady, or should we be worrying about the possibility that globalized finance, which used to be the ally of ICT producers, may in the end destabilize national economies around the world, both North and South.

\section{A SHARED VISION}

During the late 1990s the response to all of these questions was relatively unanimous. Depending on the community of views to which they adhered, experts and political leaders believed that the marriage of information and telecommunication techniques (best exemplified by commercial usage of the Web) would pave the way for a durable recovery in productivity gains; ensure strong growth in markets conquered by the more traditional industries (in activities such as materials transformation, logistics or services); and/or facilitate corporate management by adjusting production 'digitally' to the slightest variation in demand. This was expected to transform the economic cycle, and maybe even eliminate it in countries that were capable of mastering the emerging technological paradigm.

At the same time people were warned about a 'digital divide' if education and training failed to facilitate access to ICT, this being considered a first step towards the fulfilment of 'the knowledge economy'. There was little confidence in those countries that had been unable to come to grips with the 'information revolution' because they had not adopted the collective institutions and organizations that seemingly underpinned the success of a place like Silicon Valley: namely, close relationships between university staff and company 
founders; a sufficient quality and volume of venture capital; liquid and deep financial markets (to allow start-ups to float their capital on the stock market within a very short period of time); highly mobile individuals bearing requisite competencies; and little taxation on capital gains and profits. Governments would therefore have a simple task: to acclimatize, as best and as quickly as possible, the equivalents of the organizational and institutional discoveries that were shaping the US economy's longest growth phase of the post-1945 era.

\section{BEYOND THE MYTHS}

This book subjects such propositions to critical dissection. Few emerge unscathed. It contests the relevancy and generality of the various propositions, basing its criticism on a detailed examination of the hypotheses on which they were built.

From the very outset, the 'new economy' aggregates under one and the same title a whole range of activities embracing a wide array of characteristics, even if they all involve ICT. It is no surprise that this 'fiction' of the new economy ultimately imploded during the 2001-2002 recession in the USA.

Adopting ICT is not a sufficient condition for improving corporate productivity. There needs, in addition, to be a reorganization of the information and decision-making channels of companies so that firms can benefit from the production of public goods in research, education and those infrastructural forms that ensure the competitiveness and adaptability of private agents.

Forecasting errors do not necessarily decrease as a result of ICT, nor does the macroeconomic cycle disappear. Over-accumulation and the speculation that accompanies it, as well as belief in a new era rather than rational calculations and expectations - all of these factors have quite logically led to a recession. Prognoses by many experts and financiers, as witnessed by new market share prices, have been cruelly refuted.

Europe is not uniformly and irretrievably lagging behind the USA. Small and open social-democratic economies such as Finland and Denmark have posted excellent results thanks to the way in which they control the usage and/or production of ICT. This is so even though their institutions are very different from those found in the USA. In these countries, prevailing strategies are based on cooperation rather than the fomentation of radical competition. Such strategies do not harm their international competitiveness; far from it, especially as it now seems that new financial markets are not really necessary.

All in all, there is nothing inevitable about the digital divide. It is true that inequalities can worsen in economies where the logic of competition prevails, notably in the United States. But the Scandinavian economies are there to remind us that this danger is not inherent to ICT. Instead, it is directly 
conditioned by ambient notions of social justice, by institutional arrangements that govern the distribution of income and, more generally, by forms of solidarity. Down with technological determinism! Economic and social policies have to account for the possibility of innovation-related constraints; but these are certainly not solely determined by innovation.

Some countries will benefit from the new technological possibilities, using them to forge suitable institutions. They will do so through negotiation and by political compromise - itself a vector of innovation for rules and interventions. Some countries may find it easier to fit into emerging growth regimes than those suffering from inertia resulting from success during preceding phases of growth: examples include Ireland, and to a lesser extent Portugal. In other words, the line of demarcation between development and non-development is not set once and for all.

The US economy snowballed during the 1990s, and this may have created the illusion of a virtuous circle between financial innovation and ICT. Market traders believed that this sector was destined for a glorious future, and took large buying positions in it. Reciprocally, start-ups found it easy to turn to stock market funding. Far from ensuring an efficient allocation of capital, however, this synergy led to a speculative snowball effect, one that was doomed to collapse at some time due to the over-accumulation it caused, and notwithstanding the best efforts of the US Central Bank (the Federal Reserve). In actual fact, irrational exuberance was the correct thesis, not market efficiency or the disappearance of cycles.

\section{A KALEIDOSCOPIC APPROACH}

These conclusions reflect the convergence between a series of varied approaches that have tried to discern emerging growth model issues in a complementary fashion.

To begin with it is important to determine the conditions in which the 'new economy' theme emerged, because it was this that induced technological change and industrial economics specialists, along with network analysts, macroeconomists and historians, to come up with a whole host of approaches and analyses (Chapter 1). One of this book's main arguments is that excluding the network infrastructure hardware, computer and software-producing sectors, ICT affects a company's management before it impacts on its production or distribution processes (Chapter 2). It is only after this has been understood that we can attempt to ascertain the circumstances and mechanisms that contributed to the recovery of productivity, particularly in the USA (Chapter 3).

During the 1990s, benchmarking comparisons focused on other national economies instead of on other companies, with the US economy usually 
depicted as the ostensibly obligatory point of reference. However, if we were to define this benchmark in a much broader manner, perhaps by asking whether the country in question had entered a virtuous circle of growth, our conclusions would be quite different. The geography of the 'new economy' is rich in lessons about the nature of the institutions that allow for renewed growth (Chapter 4). An international comparison of the main OECD countries is particularly enlightening with regard to the specific US path taken between 1991 and 2000. Many transformations took place in areas such as competition, industrial relations, financial organization, taxation and social protection. When combined with technological innovation, they played a part in shaping an institutional architecture that was very different from the one that had prevailed during 'the golden age of growth' after 1945 - the so-called Trente glorieuse ('30 glorious years') - or even that which had existed during the 1980s (Chapter 5).

Many lessons can be drawn by observing the chain of events that took place between March 2000 and January 2003. Some of the founding myths of the 'new economy' were quickly reassessed to the extent that nowadays the term itself is often used only in reference to the past. Although the recession did not put paid to the diffusion of ICT, it reminds us of some of the key lessons of economic history. There may be a succession of financial crises associated with the innovations that allegedly typify each era, but these crises are all different (Chapter 6). Lastly, although we can accept that ICT has brought about fundamental changes in the way that companies (and public administrations) are managed, questions need to be raised about the meaning of abandoning the distinction between 'old' and 'new' economies for the future development of the different productive models that continue to coexist, depending upon sector or country (Chapter 7).

My analysis goes on to present, and to take a critical look at, the likelihood of several prognoses relating to the redeployment of information technology. In the process, I assess whether this helps identify potential successors to the model envisaged by the proponents of the 'new economy'. This will be a chance to situate the transformation of the 1990s against the backdrop of the long history of the US economy, and by so doing come up with a prediction as to the probability of an anthropogenetic approach to growth (Chapter 8).

A brief conclusion will draw out some general lessons. This is in the hope that they will help both private actors and public decision-makers to decipher the complex developments which characterize the emergence of original growth regimes for which ICT is the instrument and point of passage, but not the driving motor. 